\title{
Educação do corpo feminino: um estudo na Revista Brasileira de Educação Física (1944-1950)
}

CDD. 20.ed. 616.89

\author{
Marcelo MORAES E SILVA* \\ Mariana Purcote FONTOURA* \\ *Universidade Estadual \\ de Campinas. \\ **Universidade Federal \\ do Paraná.
}

\begin{abstract}
Resumo
0 presente trabalho tem como objetivo analisar os discursos especializados sobre o corpo feminino vinculados a um importante periódico da Educação Física brasileira da década de 40: "A Revista Brasileira de Educação Física". As práticas corporais e desportivas eram vistas como conquistas para as mulheres, mas ao mesmo tempo podiam colocar em risco o projeto de "ordem" e "progresso" e a própria representação de feminilidade vigente. Então, foram colocadas em ação várias retóricas discursivas que apontavam restrições à inserção feminina neste universo. A principal justificativa apresentada nas páginas da revista era o fator biológico, baseado principalmente nas diferenças anatômicas e fisiológicas, bem como em um excessivo medo da virilização da mulher. A título de conclusão, o trabalho aponta que, apesar das enormes limitações impostas às mulheres dentro das práticas corporais e desportivas, o seu ingresso neste universo representou uma conquista devido ao fato da sua saída do espaço privado do lar e entrada na esfera pública.
\end{abstract}

Unitermos: Educação do corpo; Revista Brasileira de Educação Física; Mulheres; Saber médico.

\section{Primeiras palavras}

Com o crescente processo de urbanização e industrialização ocorridas no ocidente a partir do século XVIII, emergiram outras maneiras de se enxergar a vida. Vigarello (1978) argumenta que novas formas de perceber os corpos foram elaboradas, fator que possibilitou o surgimento de novos discursos que passaram a ser empregados visando adaptar os indivíduos ao novo modelo social. A partir disso, verdades foram construídas baseadas principalmente no discurso científico de cunho biológico e médico. A higiene se tornou uma importante pedagogia de controle dos corpos. As ginásticas e os esportes foram práticas acionadas como formas de comportamento desejáveis e úteis.

Essas pedagogias acabaram por delimitar o papel feminino dentro do universo das diversas práticas corporais. Desde a interdição completa até a autorização com diversas limitações, o saber médico interferia com suas prescrições na presença feminina. Afinal, era preciso realizar investimentos para o controle dos hábitos cotidianos de todos os indivíduos, sejam eles homens ou mulheres. Novas formas regradas pelo saber médico atribuíram ao universo feminino outros papéis no cenário social. Com isso, vários mecanismos discursivos foram acionados e postos em ação para que tais prescrições fossem absorvidas pelas mulheres.

Diante deste quadro, vêm à tona algumas questôes. Quais foram esses discursos médicos e pedagógicos que incidiram sobre as mulheres? Quais eram as finalidades destas retóricas? Que estratégias foram usadas para colocar em ação seus objetivos e qual a relação desses discursos com a Educação Física? Nesse sentido, o presente artigo tem como objetivo analisar de que maneira tais questōes foram expostas em um periódico importante da Educação Física da década de 40 - a Revista Brasileira de Educação Física. 


\section{A Revista Brasileira de Educação Física}

Existe a necessidade de se compreender a palavra impressa não apenas como registro do que aconteceu, mas como parte constituinte do acontecimento, como uma força ativa na história que registra ao mesmo tempo em que se produz novas culturas, local em que se pode perceber a disputa entre o velho e o novo, em que bens culturais são produzidos, feitos veicular e apropriados. (Schneider \& Ferreira Neto, 2004, p.50).

A Revista Brasileira de Educação Física teve sua primeira edição no mês de janeiro de 1944. A justificativa apresentada para a sua publicação foi a crescente valorização que a área vinha recebendo do governo federal, desde a década de 30 . Entre as ações governamentais, pode-se destacar a prática obrigatória dos exercícios físicos nos estabelecimentos de ensino secundário; a criação da Divisão de Educação Física (DEF), pelo Ministério da Educação e Saúde (MES); e a fundação da Escola Nacional de Educação Física e Desportos, no Rio de Janeiro. Sendo esta, uma instituição de ensino superior que tinha como finalidade formar professores e técnicos capazes de orientar e dirigir a prática dessa atividade, em diferentes ambientes educacionais. Entretanto, apesar de exaltar tais medidas, o periódico em questão procurava denunciar a disparidade entre as leis e a realidade encontrada em todo o território nacional.

Formar uma consciência exata dos benéficos efeitos dos exercícios sobre o desenvolvimento harmonioso do organismo humano nem a convicção de sua necessidade absoluta para a formação integral do homem moderno, sem o que, aquelas leis, por mais sábias e justas que nos pareçam, encontrarão, grandes reações e dificilmente chegarão a ser cumpridas. (REVISTA Brasileira de EducaÇÃo Física, 1944, n.1, p.2).

Para a revista, a formação dessa convicção e a criação dessa consciência sobre a importância da Educação Física no país seriam o ponto de partida para o encaminhamento do problema. Sua linha editorial tinha a visão de que só um trabalho sistematizado, continuado e inflexível poderia extinguir a "animosidade, injustificável, mas sensível, contra as exigências resultantes da aplicação das leis que regulam a prática dos exercícios físicos nos estabelecimentos de ensino" (Revista Brasileira de EducaÇão Física, 1944, n.1, p.2). A Revista acreditava que a imprensa seria o melhor meio de conseguir o intento da propaganda da Educação Física, pois era considerado o veículo mais seguro de divulgação de ideias, de alcance mais geral e efeitos mais duradouros (REVISTA BRASILEIRA DE EDUCAÇÃo FísICA, 1944, n.1).

De acordo com o capitão do exército João Barbosa Leite, primeiro diretor da revista e primeiro diretor do Departamento da Educação Física do Ministério da Educação e Saúde, o periódico seria uma expressão da vontade do superintendente Cel. Luiz Carlos da Costa Neto. Representaria, também, um esforço no sentido de dar maior amplitude à cooperação educativa que existia entre o governo e algumas instituições particulares, fato que colaborava com a grande obra de revigoramento físico, moral e intelectual da mocidade brasileira.

Pela difusão dos conhecimentos acumulados sôbre a matéria de sua especialidade, pela propagação e defesa dos idéais modernos que inspiraram a estrutura educacional do nosso país, assim como pela divulgação esclarecida dos atos governamentais interessantes para os leitores. Colaboração, enfim, no sentido de proporcionar os debates mais amplos em tôrno dos assuntos controvertidos, à feição da índole e dos sentimentos democráticos de nossa gente (REVISTA Brasileira de Educação FísIca, 1944, n.1, p.3).

A proposta editorial era oferecer aos leitores notícias dos órgãos federais, estaduais e municipais, além de informações referentes às escolas de Educação Física. Assim, publicava textos de autores clássicos sobre a área (estrangeiros ou nacionais), bem como colaborações distribuídas pelas seções filosófica, técnico-pedagógica, técnico-biológica, técnico-desportiva, administrativa, de consultas, complementada com a divulgação de curiosidades sobre Educação Física e indicação de bibliografia especializada (REVISTA BRASILEIRA DE EdUCAÇÃo FísICA, 1944, n.1, p.2).

A revista acompanhava todas as conquistas da Educação Física no país. Apoiava e criticava as diversas ações do governo dentro da área. Por exemplo, no seu exemplar de n.10, apresentou como uma grande conquista a aprovação do projeto de aperfeiçoamento físico do funcionário público. Esta ação abria espaços para o reconhecimento do papel da área na formação dos indivíduos modernos, como a organização de um Departamento de Ginástica e Desportos, que coordenavam programas de atividades físicas, os quais culminaram com a criação dos "Jogos dos Servidores Civis do Brasil" (REvisTa BrasileIra de EdUCAÇĀo FísICA, 1944, n.10, p.1).

Com vistas a disciplinar e educar os corpos, a Educação Física brasileira contribuiria para formar 
uma nova nação urbana e industrial. Como se pode comprovar pelo trabalho de SOAREs (2008), desde as primeiras décadas do século XX, as cidades brasileiras, sintonizadas com teorias e correntes de pensamento desenvolvidos na Europa e Estados Unidos, foram invadidas por um ideário de saúde que incluía a prática de exercícios físicos e esportes. Estas práticas, resultado de uma sofisticação e especialização de discursos, visavam educar os corpos para um mundo urbano cada vez mais ascendente no território brasileiro.

Pela luta que estava empenhada pela causa da Educação Física no Brasil, o periódico analisado, por vezes mostrava a sua grande insatisfação com as perspectivas de grandes mudanças no Ministério da Educação e Saúde, e nas administrações dos estados. Tal postura se devia, principalmente, por estes órgãos aprovarem leis que, na visão da Revista, eram contra o que a área teria conquistado até então, como por exemplo: o "decreto lei que aboliu a obrigatoriedade da frequência às sessões de exercícios físicos como condição básica para admissão aos exames finais das disciplinas curriculares" (REVISTA Brasileira de Educação Física, 1946 n.24, p.1). Também fazia críticas contundentes aos interesses individuais dos políticos na área da Educação, e às impossibilidades de funcionários especializados, com conhecimentos de ordem técnica, científica e filosófica desempenharem suas respectivas funções.

Neste viés, o diretor da revista, Inezil Penna Marinho $^{1}$, ex-chefe da Seção Técnico-Pedagógica da Divisão de Educação Física, do Ministério da Educação e Saúde, argumentou em uma carta aberta ao Ministro da Educação e Saúde:

A Educação Física deixou de ser no Brasil, um problema técnico para se tornar uma questão política... não sacrifique o interesse de milhões de brasileiros, aos interesses subalternos de uma dezena de indivíduos... Pobre Brasil! Estás asfixiado pela política dos maus políticos! Em tuas terras a ciência e a técnica devem estar a serviço dos aduladores e da política administrativa! (REVISTA Brasileira de Educação Física, 1946, n.32, p.1.).

Paralelamente a este panorama geral do periódico, podem-se estabelecer algumas fases por que a revista passou ao longo de suas edições ${ }^{2}$.

A Revista Brasileira de Educação Física sofreu uma crise no ano de 1946, principalmente devido ao fim do Governo Vargas e à consequente transição do regime ditatorial ao democrático. Como resultado desse fato, em abril do mesmo ano, a empresa "A Noite", responsável pela rodagem do periódico, suspendeu a sua circulação. Contudo, a equipe editorial resolveu arcar com todas as responsabilidades. Só que, a partir desse momento, a edição passou a ter recursos mínimos, pouquíssimos anunciantes e um reduzido número de assinantes. A situação melhorou somente após um ano de trabalho da equipe editorial, o que permitiu elevar o número de assinantes de 156 para mais de mil, estabelecendo com isso uma rede de representantes nacionais e internacionais. Aumentar o número de páginas de 32 para 44, dobrar a tiragem, melhorar a qualidade do papel e emprestar novas características à Revista foram as principais medidas tomadas pela nova direção. Após essa nova política editorial, a revista alcançou a incrível marca de mais de 300 assinantes em países estrangeiros, e era considerada por Inezil Penna Marinho o periódico nacional de maior circulação fora do país (REVISTA Brasileira de EducaÇÃo FísICA, 1947, n.38).

Cumprindo um arrojado programa de expansão, em maio de 1947, na edição n $^{\circ} 38$, a Revista lançaria a campanha dos 10.000 assinantes, que se estenderia por todo o território nacional e posteriormente pelo restante da América e da Europa. Solicitavam a cooperação de cada um de seus leitores e anunciantes, para que fizessem propaganda e transformassem outros indivíduos em novos assinantes, justificando que "na convicção de que estará colaborando não apenas no êxito de uma campanha, mas para a vitória de uma causa verdadeiramente nacional" (REVISTA Brasileira de EducaÇÃo FísICA, 1947, n.38, p.1).

A partir do exemplar no 39, o periódico passou a ser remetido a todos os deputados e senadores da República, bem como os vereadores do Distrito Federal. $\mathrm{O}$ intuito era de que, ao receberem os exemplares, as autoridades acabassem concordando com as maiores necessidades da população, que, segundo a Revista, eram educação e saúde. Conforme aponta SOARES (2008), no imaginário desse período a Educação Física seria o veículo que atenderia simultaneamente a essa dupla tarefa. Promover a saúde, a educação e regenerar a raça eram fatores considerados fundamentais para impor a ordem e a disciplina. $\mathrm{O}$ objetivo central era o de construir um ambiente favorável à Educação Física no Brasil, principalmente na sua relação com o poder executivo e legislativo. Segundo a equipe editorial da Revista, enviar o periódico a essa esfera do poder poderia fornecer, aos representantes do povo, material para a reflexão de que a Educação Física seria uma prática importante para a constituição de um país moderno e avançado. Assim, a partir de novembro de 1947, foi iniciada a campanha de propaganda da Educação Física, na qual foi ampliada a distribuição a todos os Ministros 
de Estado, Governadores, Secretários de Educação, Diretores de Departamentos de Educação, Membros do Conselho Nacional e Estaduais de Educação, Reitores de Universidades e dos Diretores de Repartições do Ministério da Educação e Saúde (REvista Brasileira de EdUCAÇão FísICA, 1947, n.44).

Em suma, até 1948, a Revista vivenciou três fases principais. $\mathrm{O}$ seu primeiro número, em edição de 2.000 exemplares, surgiu em janeiro de 1944, com 64 páginas e, no mês seguinte, seus assinantes se elevaram a 300. A segunda fase está caracterizada pela desvinculação com a empresa "A Noite", com tiragem de 1.000 exemplares, 32 páginas e 156 assinantes. $\mathrm{Na}$ terceira fase, recuperando-se da crise, se encontrava com tiragem de 5.200 exemplares, 60 páginas e mais de 2.000 assinantes. Neste período, a revista passou a interessar também ao grande público, ou seja, àqueles que não estavam diretamente ligados à Educação Física (Revista Brasileira de Educaçấo FísICA, 1948, n.46).

A sua circulação não se limitava ao Brasil, estendiase aos demais países da América Latina, aos Estados Unidos, Portugal e África oriental. Havia seções mantidas em língua espanhola, com a colaboração de intelectuais de diferentes países, o que dava à Revista um caráter pan-americano. Era também um órgão oficial de pronunciamento de várias instituições ligadas à Educação Física, entre elas o Comitê Nacional do Instituto Pan-americano de Educação Física,
Federação Brasileira das Associaçôes de Professores de Educação Física, Associação de Professores de Educação Física do Rio de Janeiro, São Paulo, Paraná, Rio Grande do Sul, Pernambuco e Minas Gerais.

Em 1950, a Revista encontrava-se em uma situação financeira e econômica consolidada. Dentro da política pela causa da Educação Física, ampliava-se a elaboração de cursos de aperfeiçoamento sobre Educação Física e Técnica Desportiva, bem como o estreitamento com campanhas educacionais e órgãos vinculados ao Ministério da Educação e Saúde. A Revista apresentava um excelente panorama esportivo da década de 40, no Brasil; dos temas que animavam as discussões sobre os conteúdos a serem tratados pela Educação Física; e do lugar dessa disciplina no cenário educacional.

Dentro do contexto histórico analisado neste estudo, notou-se que a Revista Brasileira de Educação Física exerceu um forte papel como ferramenta para o desenvolvimento e disseminação dos saberes científicos. Tinha como premissa, em várias de suas ediçôes, a melhoria do panorama educacional, higiênico, sanitário e eugênico da população. Nesse cenário, representou os desejos e obstáculos com que se deparava a Educação Física no Brasil, no período em questão. Inclusive, nas suas páginas se demarcava como seria a participação feminina no universo das práticas corporais.

\section{A presença feminina na Revista Brasileira de Educação Física}

As mães fortes são as que fazem os povos fortes. É de toda necessidade a educação física das meninas para desenvolver, o santuário da maternidade (REVISTA Brasileira de Educação FísICA, 1944, n.2, p.41)².

A Revista, ao longo de suas edições, publicou vários artigos, matérias, e citações relacionando a mulher com sua principal e nobre missão: a maternidade. Era do sexo feminino que dependia a geração e a criação de filhos robustos que passariam a servir a nação, integrantes do "Brasil de amanhâ". Os conteúdos das publicações produziram "verdades" acerca das qualidades e modos de ser das mulheres. As representações estavam relacionadas aos ideários do higienismo e eugenismo, incorporadas de um discurso de caráter nacionalista. Os preceitos higiênicos podiam, não só melhorar as condições individuais de saúde, como também aperfeiçoar eugenicamente as novas geraçōes através de cuidados especiais ministrados às futuras mães e aos recém-nascidos. Almejava-se o aumento do índice nacional de robustecimento humano, com o reconhecimento da realidade dos princípios eugênicos que deveriam ser propagados.

Ao falar da mulher, o periódico tematizou a questão da beleza, utilizando-se de determinadas retóricas que, conforme argumenta Vigarello (2006), partem de uma clássica relação desta com a saúde. A beleza foi exaltada como filha legítima da saúde, único meio no qual ela poderia florescer. Tal como aponta o intelectual francês, a obrigação de preservar o corpo, como frasco precioso onde se contém a essência do espírito, era uma característica helênica, mas, sobretudo, moderna. Símbolo da modernidade, o direito de ser bela exercitaria o ofício de aperfeiçoar, dia após dia, as qualidades de sua natureza (REVISTA BRASILEIRA DE EDUCAÇão FísICA, 1946, n.31).

As atividades física sistemáticas são invocadas como elemento central no processo de embelezamento, dotando o corpo de belos atributos, 
uma técnica que compartilha das regras da Higiene, representando importante auxilio à saúde da população (Silva \& Goellner, 2008, p.255).

$\mathrm{O}$ médico higienista deveria trabalhar de mãos dadas com o pedagogo e com o professor de Educação Física. As praias, os ginásios, as piscinas e os clubes esportivos passaram a ser considerados escolas de saúde.

A beleza crescente das gerações novas reflete a eficácia dos novos métodos de educação, no Brasil. Uma visita às praias convence-nos facilmente de que se está plasmando, uma unidade étnica admirável (Revista Brasileira de EducaÇão FísicA, 1946, n.31, p.4).

A normalidade, traduzida como beleza, seria o desenlace dos pressupostos eugênicos - atributo muito raro em um país de mestiços como o Brasil. Ser bela, com o corpo saudável refletia objetivos que iam além de sua própria materialidade. Vista como peça fundamental para o engrandecimento do país, a representação maternal estava voltada para o fortalecimento da raça, no que diz respeito à saúde, ao vigor físico e à eficiência frente aos obstáculos da vida. Segundo GOELLNER (2003), as mulheres deveriam reconhecer a importância das práticas corporais, a fim de favorecer o aperfeiçoamento da reprodução humana e, ao mesmo tempo, preparar os jovens, mantê-los dispostos para a luta e para exibir a força de seu patriotismo. Para que tal fim se concretizasse, a Revista tomou para si o dever de divulgar a Educação Física feminina, através dos mais modernos preceitos científicos e pedagógicos, vendo nas mulheres a possibilidade de robustecimento da população e "melhoria do padrão humano nos anos do porvir" (REVISTA BRASILEIRA DE EDUCAÇÃo FísICA, 1946, n.31, p.4).

A educação física da mulher, alicerce básico de tôda regeneração física, constitui, pelos seus elevados objetivos e meios postos em ação, uma escola de energia individual e mais ainda social. Por isso mesmo, deve ser bastante incrementada como coadjuvante poderosa da eugenia (REVISTA Brasileira de EducaÇÃo Física, 1949, n.60, p.5).

Cabe destacar que nos artigos em que foram abordados os temas sobre a mulher, esteve sempre presente um intenso discurso médico e biológico, que justificava e delimitava as possíveis funçôes e espaços sociais nos quais o feminino poderia ou não estar presente. Os esportes e as ginásticas para a mulher eram vistos como parte da construção de seu corpo e de sua personalidade. Aos desportos, como afirmou o professor João Lira Filho, foram atribuídos "um sinal de emancipação feminina, dando sentido à sua presença, destacando sua expressão, mobilizando-a, na preparação da sua dignidade" (REVISTA BRASILEIRA DE EdUCAÇÃo FísICA, 1944, n.3, p.7).

No entanto, além de individuais, seus "benefícios" visavam a um bem maior: o de cumprir a missão de estar na condição física saudável para gerar seres fortes. Entretanto, nas publicações da Revista houve uma mistura de argumentos, uma sobreposição discursiva entre o discurso da maternidade e os relacionados ao progresso feminino na esfera pública.

Hoje todos reconhecemos que ela não nasceu com carteira profissional de cozinheira. Sua educação não se destina, apenas à função procriadora. A economia domestica é a primeira das aptidões com que deve dotar-se a mulher; não se infere porém daí, que sua vida, neste século, se concentra na administração da casa (REVISTA Brasileira de EducaÇÃo Física, 1944, n.3, p.5).

Entre trilhas e caminhos sinuosos, conforme aponta RAGO (1985), forjou-se uma representação simbólica da mulher - a "esposa-mãe-dona-de-casa" -, no mesmo momento em que novas exigências da crescente urbanização e do desenvolvimento comercial e industrial solicitaram a presença feminina em várias instâncias do espaço público. Entretanto, essa participação tinha uma série de interdições discursivas, principalmente as elaboradas pelo saber médico. Tais representações também tiveram espaço na Revista. A morfologia e fisiologia feminina surgiram em suas matérias quase como um consenso entre os autores dos artigos publicados. Segundo Goellner (2003), a Educação Física feminina deveria adaptar-se às tendências inerentes ao seu sexo. $\mathrm{O}$ corpo feminino, que se quer forte, saudável e, sobretudo útil, deveria sofrer algumas interdiçóes que objetivavam proteger características de sua feminilidade, preservando-lhe a fertilidade e, principalmente, não virilizando as mulheres. Neste viés, afinada com esse discurso, a Revista registrou em suas páginas a fala de Stella Guérios, técnica de Educação e professora da Escola Superior de Educação Física do Estado de São Paulón : No congresso Internacional de Educação Física, realizado em 1913, DEMENY ao mencionar no seu trabalho a ginástica feminina sugeriu que: é preciso pedir à mulher os esforços, mas dar a êsses esforços uma forma adaptada à sua beleza. A sua energia não deve destruir a sua graça natural, sinão ela não achará, atrativo nos exercícios (Revista Brasileira de EducaÇão FísICA, 1947, n.40, p.10).

Os atributos "naturalmente" femininos foram mencionados pela autora para especificar o trabalho físico para as mulheres. 
Devemos elevar a cultura física feminina, desenvolvendo-a o mais possível por meio das suas atividades físicas; não rejeitando os exercícios que lhes darão flexibilidade, equilíbrio, resistência, harmonia de formas, controle neuromuscular, doçura e graça e jamais permitindo que a feminilidade no sentido verdadeiro da palavra seja destruída ou esquecida. A força deve ser desenvolvida, mas até certo grau, para que não destrua uma atitude bela (REvisTA BrASileira de Educaçāo Física, 1947, n.40, p. 1).

A mulher deveria ser "forte" até certo ponto, não ultrapassando os limites ditados por sua "natureza”. O aumento excessivo de massa muscular era "indesejado", pois era considerado destituído de graça e harmonia, além de estarem relacionados a certas características viris que questionam a beleza e feminilidade da mulher, colocando em dúvida a autenticidade de seu sexo e sexualidade. Nota-se, nesse momento, que a principal preocupação não era com a suposta essência feminina, mas com o medo excessivo da sua virilização. Trata-se de discursos que, segundo indica BuTLER (2003), procuravam manter intacta a matriz heterossexual. Assim, as matérias publicadas na revista giravam em torno da preservação dessa sofisticada máquina, denominada de heterossexualidade compulsória, e a interdição a certas práticas corporais visavam manter tal dicotomia 5 .

Todos os atributos, sejam eles masculinos ou femininos, deveriam ser guiados por essa importante matriz. Seguindo tal perspectiva, visualizou-se que os discursos biológicos, oriundos do saber médico, eram os demarcadores das funções, características e espaços que os indivíduos, principalmente as mulheres, deveriam ocupar no plano cultural. Em quase todos os artigos sobre Educação Física feminina, estava presente o discurso de cunho médico, conforme pode ser comprovado nas palavras de Stella Guérios:

Verificamos quão evoluída está a vida privada e social da mulher e como esta necessita de uma educação física racional e progressiva. Nela, a falta de atividade física é de conseqüência bem mais desagradável do que para o homem, atendendo a que sua vida pessoal será repercutida na geração (Revista Brasileira de Educação FísicA, 1947, n.40, p.10).

Os argumentos eram sempre legitimados pela ciência e pelo discurso médico, como se pode ver na citação do Dr. Maurice Boigey:

Para uma mulher uma inteligência cultivada acompanhada de uma má constituição é de pouco valor, porque a descendência de uma doença é destinada a se estender da $1^{\circ}$ a $8^{\circ}$ geração. Ao contrário, uma boa constituição si forem pobres os dons intelectuais que acompanham merece sobreviver. Porque a inteligência, pode ser, indefinidamente, cultivada nas gerações futuras, enquanto que a saúde perdida não é recuperada. Não há portanto, como deixar de concluir que: cultivando-se o valor fisio-psíquico e social da mulher, toda a raça será melhorada, porquanto ainda: É uma mulher forte que faz uma raça forte e são as mulheres belas as responsáveis pela beleza de uma raça forte (REvista Brasileira DE EduCAÇÃo FísICA, 1947, n.40, p.10).

Assim, a revista mostrou-se bastante próxima dos argumentos científicos, sendo que estes lhes davam validade e indicavam os lugares que cada indivíduo poderia ocupar na cena social.

\section{Ordem médica: delimitando os tempos e espaços das mulheres}

Segundo Dalben e SoAres (2008), o saber médico, na década de 40, produziu uma série de regras de condutas e formas de pensar específicas. Seus ensinamentos colocavam-se como necessários para todos. Em conjunto, alguns periódicos, como a Revista Brasileira de Educação Física, formaram um eficiente meio de divulgação e propaganda do saber médico para a sociedade, afirmando-o como verdadeiramente responsável por educar, corrigir e curar o corpo.

As matérias da Revista relacionadas às práticas corporais indicadas às mulheres eram sempre assinadas, permeadas e legitimadas pelo saber médico. A retórica médica, presente nelas, estabelecia um compilado de "verdades" sobre os corpos femininos, seus usos higiênicos, eugênicos e morais, regulamentando suas açôes em todas as esferas da vida. Os médicos permitiram o ingresso das mulheres no universo das práticas corporais, porque viam nele uma ferramenta importante para o desenvolvimento da saúde e da beleza feminina; um instrumento fundamental para o desenvolvimento da maternidade sadia. Entretanto, conforme aponta COSTA (1983), a retirada da mulher do confinamento doméstico, liberando-a para o convívio social, deveria ser regulada, para que não 
prejudicasse a estrutura familiar tão bem planejada pela ordem médica. Pode-se aqui fazer um paralelo com a afirmação de RAGO (1985, p.63):

A invasão do cenário urbano pelas mulheres, no entanto, não traduz um abrandamento das exigências morais [...] Ao contrário, quanto mais ela escapa da esfera privada da vida doméstica, tanto mais a sociedade burguesa lança sobre seus ombros o anátema do pecado, o sentimento da culpa diante do abandono do lar [...] Vários procedimentos estratégicos masculinos, acordos tácitos, [...] tentam impedir sua livre circulação nos espaços públicos.

Cabe destacar que, conforme aponta Luz (1988, p.94), as concepçôes predominantes do pensamento médico no Brasil, nesse período, foram aquelas que se constituíram a partir de: “(...) teorias e categorias higienistas, com profundas implicações moralizadoras, com propostas políticas implicando adaptaçóes dos sujeitos, grupos e classes às regras médicas em um processo de racionalização da civilização". Sem exceção, a ordem médica destacou a importância de uma Educação Física que trazia em seu interior a prática de exercícios ginásticos, de jogos ao ar livre, de esportes e danças. Tais aspectos contribuiriam para a formação de hábitos higiênicos e na moralização dos costumes e comportamentos, orientando os indivíduos para a ocupação útil e regrada de seu tempo. Nos artigos publicados na Revista, os médicos deveriam orientar e limitar as práticas corporais condizentes com as mulheres. Jair Jordão Ramos alertava para essas orientações e limitaçôes, sob o ponto de vista da ordem médica:

A prática desportiva não deve ser feita de uma maneira empírica. Torna-se necessário ver nela [...], o cerceamento dos exercícios físicos, só convindo, por conseguinte de uma maneira absoluta, às moças em perfeito estado de higidez. Além disso, se praticados com certa intensidade, os desportes devem estar sempre sob as vistas de um médico experimentado que verificará constantemente o treinamento (REVISTA BRASILEIRA DE EduCaÇÃo Físıca, 1949, n.60, p.5).

A ciência médica se encontrava numa posição privilegiada. Proclamava um conjunto variado de justificativas e argumentações favorecendo ou contrariando certas práticas corporais. Para isso, a anatomia, a antropometria e a fisiologia foram usadas como os saberes objetivos e irrefutáveis sobre o "normal" funcionamento do corpo, bem como sobre as "naturais" diferenças entre os sexos ${ }^{6}$. Foi nesse contexto que a Educação Física contribuiu fortemente para "a grande obra de perpetuação da espécie” (Mejía, citado por SCHARAGRODSKY, 2008, p.113). A ginástica e as demais práticas corporais (jogos, danças, caminhadas, exercícios físicos moderados) auxiliaram na formação de corpos femininos saudáveis e preparados para o ofício da maternidade - fim supremo da vida de qualquer mulher considerada "normal" naquela época.

Os exercícios físicos, amparados na "ciência" médica, adquiriram rapidamente uma importância significativa, legitimados em seu potencial regenerador e em sua benéfica capacidade de intervenção, com o fim de alcançar uma "saudável" capacidade maternal. Como parte da Educação Física, os esportes, embora não ainda por unanimidade, eram considerados o equivalente da modernidade, garantia moral de esplendor, evidência de um progresso que estava alojado no coração das nações. Esta prática, conforme aponta SOAREs (2008), inscrevia novos códigos utilitários nos corpos, e representava uma possibilidade de passatempo, um entretenimento absolutamente regrado, disciplinado e universal que ensinava a obediência e a hierarquia, a precisão dos gestos e o tempo exato de duração - um elemento indiscutível de promoção da saúde individual e social.

Motivados por essas ideias, médicos como Waldemar Areno, professor catedrático de Higiene Aplicada da Escola Nacional de Educação Física e Desportos da Universidade do Brasil, publicaram retóricas que incentivavam as mulheres a sair do espaço doméstico e "adentrar" ao mundo das práticas corporais:

Como meio de Educação Física, são os desportos as atividades mais atraentes e sedutoras, movimentando as alavancas do corpo exercitando as qualidades morais e favorecendo a secreção do espírito - são práticas educacionais, recreativas e ainda como meio de competição. A competição desportiva entre as mulheres pode ser permitida e deve mesmo ser aconselhada; tem influência na formação do caráter educa o ânimo e a vontade, desperta o espírito de solidariedade e cooperação, a coragem e a confiança em si (REVISTA BrASILEIRA DE EdUCAÇÃo FísICA, 1947, n.34, p.31).

No entanto, as mulheres deveriam se adequar ao universo esportivo não de forma plena, mas sim de modo parcial. A limitação discursiva circulava nas fronteiras biológicas da materialidade anatômica dos corpos, ou seja, nas características que o saber médico considerava como "naturalmente" femininas. Nesse contexto, surgem novamente consideraçōes de Waldemar Areno:

O diformismo dos sexos é evidente e irrefutável; a mulher não difere ao homem só no seu aspecto morfológico, por ter ossos mais delicados, bacias mais largas, músculos menos potentes e fórmas 
arredondadas..., não só nas funções, mas também em várias facetas do seu espírito, está bem caracterizada a individualidade feminina (REVISTA BRASILEIRA DE EduCAÇÃo FísicA, 1947, n.34, p.31).

Os argumentos médicos converteram o corpo da mulher em um objeto de conhecimento. Era necessário controlar o seu corpo, pois certos "descuidos" poderiam virilizá-lo em demasia, colocando sua heterossexualidade em risco. Tais questôes estavam claramente expressas nos diversos artigos da Revista. O discurso da diferenciação biológica entre homens e mulheres, bem como a consequente distinção de exercícios físicos prescritos para um e outro sexo, era uma marca presente no periódico. Novamente, o saber médico esteve representado nas palavras de Waldemar Areno:

É fundamental que se obedeça à adaptação higiênica e fisiológica dos exercícios e desportos, impugnando os contra-indicados, selecionando os permitidos, orientando e regulando a execução deles. É imperioso também obedecer ao tipo morfológico feminino para a indicação de certos desportos e ainda preparar com exercícios ginásticos bem dirigidos uma sólida base física deste organismo (Revista Brasileira DE EduCAÇÃO FísICA, 1947, n.34, p.31).

Os desportos deveriam se aproximar e, sobretudo, reafirmar o universo feminino, desde a harmonia de suas formas até os recônditos de sua delicadeza. Os efeitos resultantes de sua prática não poderiam prejudicar o seu desenvolvimento anatômico e fisiológico. Aqueles que fazem da mulher um ser igual ao homem sob o ponto de vista físico, asseguram que elas podem, sem perigo algum praticar todos os desportes. Outros, ao contrário julgam que sobretudo no campo desportivo a moça deve agir com certa precaução afim de evitar sérios prejuízos à sua personalidade e a boa formação do seu físico. Aliás, esta última tese está inteiramente de acordo com o nosso modo de ver e é a consubstanciada pela nossa orientação. E, nem podia ser de outro modo, pois a mulher é na realidade, profundamente diversa do homem. Todo o seu corpo é impregnado de substâncias químicas segregadas pelos ovários, tendo cada um dos seus sistemas orgânicos os sinais característicos do seu sexo (REVISTA BRASILEIRA DE EDUCAÇÃo FísICA, 1947, n.34, p.31).

Ainda que a Revista incentivasse as mulheres a exercitarem seus corpos, os impedimentos discursivos e linguísticos a certas práticas eram muitos, pois circunscreviam a mulher nos seus limites anatômicos e fisiológicos, bem como nos da sua sexualidade heterossexual, ou seja, nas materialidades de seus corpos. Essa interdição discursiva foi marca presente nas páginas da Revista, mais uma vez na retórica de Waldemar Areno:

Existem para a mulher e de acôrdo com as condições do nosso clima, desportos indicados, contraindicados e os aceitáveis com certas adaptaçôes ou reservas. É importante salientar para êste aspecto do problema, que se estriba em fundamentos de ordem biológica e atende às finalidades a que se destina a educação da mulher (REvista BrAsiLEIRA DE EdUCAÇÃo FísICA, 1949, n.60, p.14).

As limitações discursivas narradas enfatizavam um ideal de feminilidade e um enorme medo de uma virilização acentuada. Tais anseios não se limitavam somente às páginas da Revista. $\mathrm{O}$ discurso da diferenciação biológica entre homens e mulheres, e a consequente divergência de exercícios físicos para um e outro sexo também circulavam em outros locais. Waldemar Areno, em sua obra "Fundamentos Biológicos da Educação Feminina”, publicada em 1946, registrou a necessidade de adaptação da educação feminina, fundamentada em fatores biológicos e sociais do dimorfismo dos sexos:

$\mathrm{Na}$ fase adulta são patentes as diferenças entre homem e a mulher, diferenças que, no ponto de vista anátomo-fisiológico, evidenciam logo a diversidade entre eles. No aparelho locomotor são elas bem encontradiças: na mulher, os óssos mais delicados, mas lisos, sem os acidentes de superfície tão pronunciados, cristas, saliências, apófises, para as inserções musculares e ligamentosas menos desenvolvidas; e assim se compreende, porque os músculos e ligamentos que nelas se fixam são mais frágeis e se movimentam com menor intensidade. Bacia óssea mais larga do que alta, mais ampla - o motivo é a eventual instalação do futuro tumor gravídico. [...] Articulaçōes mais lábeis, musculatura em geral menos potente e gordura mais abundante, com sua distribuição feminina, na região mamária, no ventre inferior, nos flancos e nas coxas (ARENo, 1946, p.17).

O corpo feminino foi definido como incompleto, frágil e deficiente. Para o caso da Educação Física, essa posição tradicional e inferiorizada, com respeito à condição feminina, não só foi a mais utilizada e valorizada, como também circulou nos variados discursos e nas diferentes práticas corporais, utilizadas durante boa parte do século XX. Não só a condição física das mulheres circulou nos discursos para orientar qual a melhor prática para o público feminino. Outros elementos também foram utilizados pela ordem médica, como por exemplo, os aspectos psicológicos: 
A psicologia feminina se caracterisa, diz Maranon, pelos dois seguintes traços essenciais: "uma afetividade mais aguda que a do homem; e uma aptidão menor do que dêste para a atividade abstrata e criadora. O espírito feminino é conduzido aos assuntos domésticos, às atividades morais, analíticas; ela é compassiva, tímida, afável, muito acessível ás emoções, afetuosa e sentimental. E muito embora o homem possua êsse conceito de mando, êsse complexo de superioridade, a mulher têm também as suas vantagens, os seus saldos favoraveis, nêsse confronto anatômico, fisiológico e psicológico. Ela é mais resistente á dor física, conforme podem atestar as referências de médicos e dentistas; tem maior média de duração de vida; é mais forte na adversidade, na sua dedicação à humanidade, no seu amor ao homem, na sua paciência e em seu espírito de renúncia (ARENo, 1946, p.19).

Tal discurso reforça a representação feminina de um ser muito mais sentimental do que racional. Sensível, ingênua, passiva, dona-de-casa, física e moralmente frágil, com instinto maternal e infinita capacidade de amar e de se dar. Tudo isso fazia parte de sua "natureza", uma psicologia biologizada. E foi através desses argumentos científicos, que se pretendeu fundar um novo modelo normativo de feminilidade, bem como convencer as mulheres de que elas deveriam corresponder a tais prescrições discursivas.

\section{A ordem médica no universo das práticas corporais prescritas às mulheres}

$\mathrm{O}$ universo desportivo poderia significar uma ameaça a tradicional imagem feminina. A mulher esportista punha em risco a ordem médica. Essa maior liberdade dada à mulher poderia também dissolver a família e afrouxar os laços familiares, bem como virilizar seu corpo e pôr em risco sua heterossexualidade. $\mathrm{O}$ que não aconteceria se ela ficasse no espaço privado do lar. O saber médico, então, formulou todo um discurso que delimitava demasiadamente a entrada feminina nesses espaços da vida pública. Goellner (2003, p.110) indica que tais discursos salientavam que era necessário fortalecer a "nova mulher". No entanto, velhos preceitos e juízos morais deveriam ser mantidos para que fosse assegurada a continuidade tanto da família nuclear como da distinção de papéis sociais atribuídos a homens e mulheres.

Os desportos indicados às mulheres na Revista seguiam essa lógica, tanto que Waldemar Areno classificou-os da seguinte maneira: os contraindicados, ou seja, aqueles que deveriam ser impugnados ou abolidos; os aceitáveis, que eram permitidos com reservas, sob controle médico cuidadoso; e os indicados, que eram especialmente recomendados. Entre as práticas indicadas estavam os desportos aquáticos, natação como verdadeiro desporto da mulher; natação recreativa, utilitária ou em competição, ela é benéfica no seu conjunto de ações sôbre o organismo feminino, sendo que o remo só deveria ser cultivado como meio de recreação; e o tênis, o "badmington", o tênis de mesa, e outras atividades correlatas. Entre as provas atléticas indicadas estavam as corridas rasas até 200 metros, incluindo os revezamentos e os lançamentos de dardo, disco e arremessos de peso, com material mais leve e adaptado às possibilidades $\mathrm{da}$ mulher. $\mathrm{O}$ ciclismo podia ser disputado em provas de curta duração. A equitação teria graça e elegância na sua prática, grandes efeitos gerais e um sentido utilitário e educativo, entretanto em competição deveria ser encarada com reservas. Entre os desportos coletivos, o voleibol, sendo o basquetebol também permitido, obedecendo às novas regras que procuram modelar o jogo, de modo a evitar ao máximo o contato pessoal e os choques entre as disputantes. Dos desportos de ataque e defesa, só a esgrima de florete era compatível e aceitável em competição. Das atividades úteis à mulher, não deveriam ser omitidas a dança e a patinação, principalmente a dança natural, de sentido altamente educativo, onde a graça e o encanto dos movimentos ritmados se associam aos benéficos efeitos gerais sobre o organismo (REvista BrasileIra de EdUCAÇÃo FísICA, 1947, n.34, p.31-3).

No amplo catálogo dos desportos contraindicados estavam as provas aquáticas acima de 400 metros, distâncias em que só deveriam competir as nadadoras já experimentadas. Os saltos ornamentais poderiam também ser permitidos, obedecida à orientação do respectivo regulamento na seleção dos saltos femininos. O polo aquático era uma prática corporal contraindicada.

Tais interdições se materializam numa matéria escrita por Waldemar Areno:

Nos desportos terrestres individuais, há entre as provas atléticas, diversas consideraçōes a serem 
previstas. Apesar de em tôdas as provas, haver adaptação ao sexo, quer nas distâncias a percorrer, quer no material utilizado, nem tôdas parecem indicadas e permitidas à mulher. $\mathrm{O}$ próprio regulamento olímpico, não faz constar do mapa das competiçôes, as provas evidentemente absurdas, como o lançamento do martelo, as corridas até 200 metros, o salto com vara e o salto triplo. O salto em distância com impulso não pode deixar de ser encarado com reservas e sôbre ele já opinamos em contrário. $\mathrm{O}$ salto em altura e a corrida com barreiras baixas, são provas que podem ser permitidas exclusivamente às atletas de figura morfológica compatível e favorável (REVISTA BRASILEIRA DE EduCAÇÃo FísICA, 1947, n.34, p.32).

O levantamento de peso e halteres eram contraindicados, bem como a ginástica de aparelhos, apesar de ser praticada em alguns países europeus. A maioria dos exercícios de barras paralelas, argolas, cavalo de pau e barra fixa, não eram adaptáveis à mulher.

No que se refere ao esporte mais popular do país, as interdições eram ainda maiores. Os argumentos contrários à participação das mulheres no futebol explicitavam que, além de ser uma prática corporal rude, a modalidade requeria um nível apurado de preparação física e técnica, cuja prática poderia ferir o corpo feminino, principalmente no que diz respeito a sua saúde reprodutiva, a sua virilização e ao seu aspecto estético. Nas páginas da Revista, Waldemar Areno limitava a prática feminina nessa modalidade:

É evidente que o futebol não pode fazer parte dos desportos femininos, nem mesmo como, grande jôgo. Tal prática é absurda e nociva e o espetáculo que ela nos oferece, além de antidesportivo e antifisiológico é até degradante aos observadores de bom senso. Já tivemos a oportunidade e o desprazer de assistir o futebol feminino, que felizmente não teve aceitação entre nós. O hochey, o baseball e o rugby, não praticados no Brasil, pelas características de regulamentação, não são também atividades para o sexo feminino (REVISTA Brasileira de EduCaÇÃo FísICA, 1947, n.34, p.32).

Os desportos de ataque e defesa, entre eles o boxe, a luta livre, o jiu-jitsu, a esgrima de espada e sabre, não eram evidentemente meios para a conquista do fim a que se destinava a Educação Física feminina. O saber médico também era contrário à participação feminina na ginástica acrobática. Os exercícios de malabarismo e as cambalhotas eram considerados desgraciosos e antiestéticos para a mulher, além de arriscados e sem finalidade como meio de educação corporal. Novamente, Waldemar Areno foi chamado para emitir sua opinião:
Os métodos de Educação Física são pletóricos em exercícios apropriados à mulher e não há de qualquer modo necessidade de nos socorrermos de exercícios desse gênero, motivos exclusivos de exibicionismo e não meios educativos ou de recreação (REVISTA BRASILEIRA DE EDUCAÇÃo FísicA, 1947, n.34, p.33).

Percebe-se, pelas afirmaçōes presentes na Revista, que era necessário que a mulher se exercitasse, mas de forma que as características do modo feminino de ser estivessem garantidas. Assim, aquela que não obedecesse aos requisitos estipulados inscrevia-se no campo da "anormalidade". A independência da mulher não podia extravasar as fronteiras da casa. Por isso, sua presença em desportos acabava por ressaltar certa independência. Características que não eram condizentes com sua "natureza" e, por isso, eram intoleráveis e interditas. A mulher esportista poderia significar um mau exemplo às outras mulheres. Uma ameaça para sociedade. Nesse sentido, a nova mulher que o periódico deseja ver construindo a nação.

[...] deve agir dentro dos preceitos morais e culturais que sustentam este tempo de industrialização e urbanização. Se há a exigência de uma maior participação em diferentes instâncias da sociedade há, também, a diversificação das formas de controle que para ela se direcionam. Afinal, antes de se configurar como um efetivo projeto de emancipação feminina, este discurso só faz reafirmar sua conformação dentro de padrões historicamente designados como próprios da sua identidade de mulher (GoeELner, 2003, p.101).

O cenário esportivo nas páginas da Revista apresentou-se com esta contradição de restrição e transgressão, somando-se a este universo todos os sistemas de representação nele presentes que criaram padrões e significados ditos "verdadeiros", demarcando modos de ser e intervindo sobre os corpos femininos. Este corpo que no pensamento do país no período era identificado como elemento importante para a sua modernização. Território permeado por ambigüidades, o mundo esportivo, simultaneamente, fascina e desassossega homens e mulheres, tanto porque contesta os discursos legitimadores dos limites e condutas próprias de cada sexo, como porque, através de seus rituais, faz vibrar a tensão entre a liberação e o controle de emoçóes e instintos individuais. Acrescenta-se a essas interpretações a constatação de que os esportes são importantes meios de propagação de um modelo imaginário de nação e nacionalidade. E também de representaçôes de masculinidade e feminilidade (GOELLNER, 2003, p.129). 


\title{
Algumas palavras finais
}

Os discursos sobre as mulheres, materializados na Revista Brasileira de Educação Física, mostraram uma forma muito peculiar de se educar o corpo feminino. Sintonizada com esses discursos, a Revista procurou demonstrar como deveria ser gerida a Educação Física feminina, elaborando um compilado de ideias e representações cuja recorrência possibilitou a emergência de uma rede discursiva que conferiu forma e legitimidade a determinados corpos femininos. A estes foram atribuídas diversas privações que supostamente objetivavam proteger as características de sua feminilidade.

Foi notável a presença da ciência e do saber médico como legitimadores de uma pedagogia corporal do feminino. Verificou-se que a ordem médica entrou como articuladora desse processo de normalização e, apoiada por saberes advindos principalmente da anatomia e da fisiologia, produziu argumentos com o intuito de converter o corpo da mulher em um objeto de constante preocupação e controle. Tudo com o objetivo de não prejudicar ou desviá-la do seu "inato" papel feminino, bem como não virilizá-la em demasia. Mantendo, assim, intacta a matriz heterossexual. Esses elementos estavam claramente expressos nos diversos artigos da revista, pois enfatizavam o discurso da diferenciação biológica entre homens e mulheres e a consequente diferenciação de exercícios físicos prescritos para um e outro sexo.

Contudo, mesmo com todas as limitações que lhe eram impostas devido às "verdades" construídas pelos saberes científicos que permeavam a Educação Física brasileira do período, o ingresso das mulheres nas diversas práticas corporais representou um grande avanço no que diz respeito a uma maior participação na vida pública. A prática das atividades físicas possibilitou a sua saída do ambiente privado do lar - predestinação de toda mulher - para um novo panorama de possibilidades e conquistas, a vida social, ou seja, a ocupação do espaço público.

\begin{abstract}
Education of female body: a study in the brazilian magazine of physical education (1944-1950)

This study aims to analyze the specialized discourses about the female body coupled to an important magazine for the Brazilian Physical Education in the 1940's: "A Revista Brasileira de Educação Física". The body and sporting practices used to be seen as achievements for women, but at the same time they could endanger the project of "order" and "progress" and also the femininity representation in force. Thus, several rhetorical discourses were put into action, which showed restrictions on the female participation in this universe. The main justification presented in the pages of the magazine was the biological factor, based on anatomical and physiological differences, and on an excessive fear of the virilization of women. In conclusion, this work shows that, despite the limitations imposed on women within the corporal and sporting practices, their entrance in this universe represented an achievement due to the fact that they left the private space of home and entered in the public sphere.
\end{abstract}

UnITERMs: Body education; Brazilian Magazine of Physical Education; Women; Medical knowledge.

\section{Notas}

1. Inezil Penna Marinho (1915-1987) trabalhou num dos mais importantes órgãos federais ligados à Educação Física brasileira, a Divisão de Educação Física (DEF) do Departamento de Educação do Ministério da Educação e Saúde (MES). Entrou em 1939, como assistente técnico e passaria a assistente de ensino, em 1940; em 1941, já era técnico de educação e chefe da Secção Pedagógica. Sua carreira na Divisão é anterior à sua formação na Escola Nacional de Educação Física e Desportos (ENEFD), que ocorreu em 1941, instituição na qual se torna professor em 1949. Já tinha formação em Instrutor de Educação Física pela Escola de Educação Física do Exército (1938); também se diplomou 
em bacharel em Ciências Jurídicas e Sociais pela Universidade Nacional (1943), Psicologia pelo Instituto de Psicologia da Universidade do Brasil (1941), Filosofia pela Faculdade de Filosofia da Universidade do Brasil (1958). Sua biografia impressiona pelo pioneirismo da sua obra, sem dúvida uma das maiores e mais múltiplas da área da Educação Física. Suas produções teóricas envolvem temas variados, entre eles a História da Educação Física, Recreação e Lazer, Filosofia, Poesia, Infância etc. (Goellner, 2005; Melo, 2008). Deste modo, percebe-se a sua importância e influência dentro da Educação Física brasileira no período em questão.

2. O ciclo de vida da Revista Brasileira de Educação Física pode ser estabelecido desde a primeira edição, surgida em janeiro de 1944 (Ano I, n.1, jan. 1944), até a última, publicada em outubro/dezembro de 1952 (Ano IX, n.82, out./ dez. 1952) (Ferreira Neto, 2002).

3. É interessante notar que esta citação de Thandiére, na Revista Brasileira de Educação Física, também está presente na Revista Educação Phísica, outro importante periódico da Educação Física brasileira, citado por Goellner (2003, p.59) em sua obra "Bela, Maternal e Feminina".

4. É interessante salientar que os fragmentos do artigo de Stella Guérios, na Revista Brasileira de Educação Física, estão presentes também em seu livro "Educação Física Feminina”, publicado em 1974.

5. Detalhes maiores sobre a matriz heterossexual, consultar BuTLER (2003), e sobre a sua relação com a Educação Física, consultar a dissertação de mestrado de MORAES E Silva (2008).

6. Scharagrodsky, no artigo "Entre la maternidad y la histeria. Medicina, prácticas corporales y feminilidadem el Buenos Aires del fin de siglo XIX", analisa as práticas de medicalização do final do século XIX. Salienta-se que este processo ocorrido na Argentina teve bastante similaridade com o ocorrido no Brasil, bem como com as prescrições encontradas nas páginas da Revista Brasileira de Educação Física na década de 40.

\section{Referências}

ARENO, W. Fundamentos biológicos da educação feminina. Rio de Janeiro: Graphica Metrópole, 1946.

BUTLER, J. Problemas de gênero: feminismo e subversão da identidade. Rio de Janeiro: Civilização Brasileira, 2003.

COSTA, J.F. Ordem médica e norma familiar. Rio de Janeiro: Edições Graal, 1983.

DALBEN, A.; SOARES, C.L. A revista Vida e Saúde: modos de olhar e educar o corpo feminino em suas páginas (19401950). Pensar a Prática, Goiânia, v.11, n.3, p.239-50, 2008.

FERREIRA NETO, A. Revista Brasileira de Educação Física. In: CATÁLOGO de Periódicos de Educação Física e Esporte (1930 - 2000). Vitória: PROTEORIA, 2002.

GOELLNER, S. Bela, maternal e feminina: imagens da mulher na Revista Educação Physica. Ijuí: Unijuí, 2003.

GOELLnER, S. (Org.). Inezil Penna Marinho: coletânea de textos. Porto Alegre: Universidade Federal do Rio Grande do Sul/Colégio Brasileiro de Ciências do Esporte, 2005.

LUZ, M.T. Natural, racional, social: razão médica e racionalidade científica moderna. Rio de Janeiro: Campus, 1988. MELO, V.A. Inezil Penna Marinho e a Escola de Educação Física e Desportos/UFRJ. Arquivos em Movimento, Rio de Janeiro, v.4, n.2, p.179-88, 2008.

MORAES E SILVA, M. Entre a ilha deserta e o arquipélago: mapeamentos e cartografias das percepçôes de professores (as) sobre as masculinidades produzidas nas aulas de Educação Física. 2008. 215 f. Dissertação (Mestrado em Educação) - Universidade Federal do Paraná, Curitiba, 2008.

RAGO, M. Do cabaré ao lar - a utopia da cidade disciplinar: Brasil 1890-1930. Rio de Janeiro: Paz e Terra, 1985. REVISTA BRASILEIRA DE EDUCAÇÃO FÍSICA. Rio de Janeiro: Comite Nacional Instituto Panamericano de Educação Física, ano 1, n.1, jan. 1944. . Rio de Janeiro: Comite Nacional Instituto Panamericano de Educação Física, ano 1, n.2, fev. 1944. Rio de Janeiro: Comite Nacional Instituto Panamericano de Educação Física, ano 1, n.3, mar. 1944. Rio de Janeiro: Comite Nacional Instituto Panamericano de Educação Física, ano 1, n.10, outubro de 1944. Rio de Janeiro: Comite Nacional Instituto Panamericano de Educação Física, ano 3, n.24, jan. 1946. Rio de Janeiro: Comite Nacional Instituto Panamericano de Educação Física, ano 3, n.31, out. 1946. Rio de Janeiro: Comite Nacional Instituto Panamericano de Educação Física, ano 3, n.32, nov. 1946. Rio de Janeiro: Comite Nacional Instituto Panamericano de Educação Física, ano 4, n.34, jan. 1947. Rio de Janeiro: Comite Nacional Instituto Panamericano de Educação Física, ano 4, n.38, mai. 1947. 
. Rio de Janeiro: Comite Nacional Instituto Panamericano de Educação Física, ano 4, n.40, jul. 1947.

. Rio de Janeiro: Comite Nacional Instituto Panamericano de Educação Física, ano 4, n.44, nov. 1947.

. Rio de Janeiro: Comite Nacional Instituto Panamericano de Educação Física, ano 5, n.46, jan. 1948.

. Rio de Janeiro: Comite Nacional Instituto Panamericano de Educação Física, ano 6, n.60, mar. 1949.

SCHARAGRODSKY, P.A. Entre la maternidad y la histeria. Medicina, prácticas corporales y feminidad en el Buenos Aires del fin de siglo XIX. In: SCHARAGRODSKY, P.A. (Org.). Gobernar es ejercitar: fragmentos de la educación física en Iberoamérica. Buenos Aires: Prometeo Libros, 2008. p.105-35.

SCHNEIDER, O.; FERREIRA NETO, A. Estratégias editoriais, enciclopedismo, produtos e publicidade na revista Educação Physica (1932-1945). Revista Movimento, Porto Alegre, v.10, p.23-52, 2004.

SILVA, A.L.S.; GOELLNER, S.V. "Sedentárias" e coquettes à margem: corpos e feminilidades desviantes na obra de Renato Kehl. Pensar a Prática, Goiânia, v.11, n.3, p.251-9, 2008.

SOARES, C.L. Educación Física escolar en Brasil: breve historia de la constitución de una pedagogía higiênica. In: SCHARAGRODSKY, P.A. (Org.). Gobernar es ejercitar: fragmentos de la educación física en Iberoamérica. Buenos Aires: Prometeo Libros, 2008. p.17-64.

VIGARELLO, G. Les corps redréssé: histoire d'um pouvir pédagogique. Paris: Jean Pierre Delarge, 1978.

. História da beleza. Rio de Janeiro: Ediouro, 2006.

ENDEREÇO
Marcelo Moraes e Silva

R. Martin Afonso, 226 - apto. 3A 80410-060 - Curitiba - PR - BRASIL e-mail: moraes_marc@yahoo.com.br
Recebido para publicação: 09/ 12/ 2010

Aceito: 22/ 03/ 2011 